\title{
Charging Systems of Electronic Devices in Urban Open Spaces, A Need Analysis and Design
}

\author{
Soudeh Shoarinejad ${ }^{1} \&$ Parvin Shokri ${ }^{2}$ \\ ${ }^{1}$ MSc Student, Department of Industrial Design, Alzahra University, Tehran, Iran \\ ${ }^{2}$ Assistant Professor, Department of Industrial Design, Alzahra University, Tehran, Iran \\ Correspondence: Parvin Shokri, Assistant Professor. Tel: 9821-4420-2773. E-mail: pshokri@alzahra.ac.ir
}

Received: April 12, 2016

Accepted: April 25, 2016

Online Published: May 16, 2016

doi:10.5539/mas.v10n6p213

URL: http://dx.doi.org/10.5539/mas.v10n6p213

\begin{abstract}
Development of open spaces and parks with a focus on improving service level and environmental quality is one of the principles of sustained urban planning and design.This is a significant step for creating optimum conditions that may make such urban resources available to the public and bring the citizens closer to the nature. Paying attention to psychological and physiological needs of citizens in designing urban furniture is a leading way to this objective. The daily individual and social lives have, evidently, come under strong influence of the advancements of electronic instruments and mobile communication and their numerous applications. This study pays special attention to the need for charging stands in urban open spaces and parks to be used for charging common electronic instruments. The tool used in this study is a questionnaire designed with Likert scales. The data obtained in this analytical-descriptive study were analyzed using IBM SPSS Statistics 21.The results revealed a need for charging stands across city as part of the urban furniture.Considering sustainable development factors, a type of stand is designed for urban parks in Tehran.
\end{abstract}

Keywords: urban services, sustainable development, kiosk, charging portable electronic gadgets

\section{Introduction}

The present era is named Digital or Communication Age. In this era, all social and individual lives are deeply related to digital products which have a great portion in defining the life style and routine interactions; eliminated the distances between people and help in storing great amount of the information. In spite of all special features and capabilities, electronic devices need charging in numerous occasions to provide continues services.

In this study, attention is focused on charging facilities in open public spaces. In order to facilitate continuous functioning of electronic devices and gadgetries away from usual sources of power, at home or offices, there is a need for charging sources made available to everyone without limits to ensure sustained usefulness of electronic devices by eliminating any possible location or timing dependence. Provision of such services, shall free people from worrying about falling short in power and losing the utility of a tool that has become a part of daily life. Elimination of such worry shall contribute to public welfare.

Urban green spaces are among public spaces that in addition to provide interaction opportunities, encourage people to come closer to the nature due to their many natural attractions.It seems charger stands not only fulfill certain needs of digital users, but also, as part of urban furniture, increase the stay time of park regulars in these spaces and provide more opportunities for social interactions. Needless to say that health and security provisions contribute to the increased welfare and social interactions of citizens.

\section{Sustainable Development of the Cities}

The word 'sustainable' is derived from Latin sus tenere, meaning to uphold. The idea of sustainable development is born of intellectual necessity, as much as political necessity. It emerges, in fact, from problems generated by Modernism itself, including our faith in science. It follows from this proposition that the idea of sustainability reflects unease about the human condition; we use nature and the environment to mirror the discontents of human societies (Redclift, 1993).

Sustainable urban development involves raising urban living quality by making improvements in various sectors 
including ecology, culture, politics, and economy without putting any burden on future generations.This objective requires adapting a sustainable approach in urban planning and management.Sustainable approach is not limited to protection of ecosystem, purification of water, and renewable energy; it is rather a comprehensive approach that deals with many aspects of human life at present and future.It requires adaptation of practical policies that are based on long term strategies.

\subsection{Importance of Urban Green Spaces}

Urban green space provided the enclaves and sub-spaces in which users could use for having private moments, gathering activities or observing others from afar. Hence, urban green spaces are important because they represent as spaces which can promote different ethnic groups mingling and communicating (Jamirsah, 2012). Most people like to be in these green spaces and enjoy meeting and seeing other people and feel connection to the place and strong community cohesion (Peters et al., 2010).

In terms of social well-being, urban green spaces have the potential in reducing negative social behavior such as aggression and violence, thus contributing to a sense of peace and harmony and play an important role in fostering social cohesion and social identity (Dempsey et al., 2012). Any contributing factor in mental health of the young will lead to less vandalism of public property, destruction, and/or contamination of the green space.Furthermore, it may promote respect to city environment as living plants and birds are vital for livelihood of urban spaces. These developments are intended to serve as means to promote a secure sustainable development of a city.

Physical or natural characters of the green space design could influence social interaction. It has been proven that the sense of centrality of spaces, user-centric design and existence of service and facilities, such as shops and service locations, are directly influencing people's presence in such spaces (Golibnik \& Ward Thompson, 2010) and also physical features were identified as efficient design elements in outdoor spaces to encourage social interaction. Physical features can attract people to stay outdoors and engage in conversations (Shu \& Huang, 2006). Moreover different green space characters and spatial qualities promote various activities including active or passive, activities such as playing, walking or sitting on the grass (Rasidi et al., 2012).

\subsection{Sustainable street furniture}

Furniture refers to a collection of furnishing and fittings made for a specific location. Urban furniture includes any facility that is designed to provide specific services for convenience of citizens, including stands, lighting fixtures, illuminated signs, and the like.

In urban service design, adaptation of sustainable approach, may lead to application of green energy.This may, in turn, elevates people's view toward environment and encourage their further involvement in its protection and reduction of pollution. Figure1 shows sustainable chargers for portable devices as a part of urban furniture.

A central aspect of the social dimensions of sustainable development relates to social conditions and factors that shape processes of change. These "social drivers" relate to social structures and institutions that shape people's preferences, behavior and possibilities, and to agency, that is, the capacity of individuals and groups to influence change. Such values relate to human dignity and rights; sense of identity and citizenship; commitment to social justice, fairness and equality; inclusivity, tolerance and solidarity; and respect for diversity and environment. In this sense, sustainable development with its norms and values provides an ethical foundation for the global community (Dugarova \& Utting, 2013).

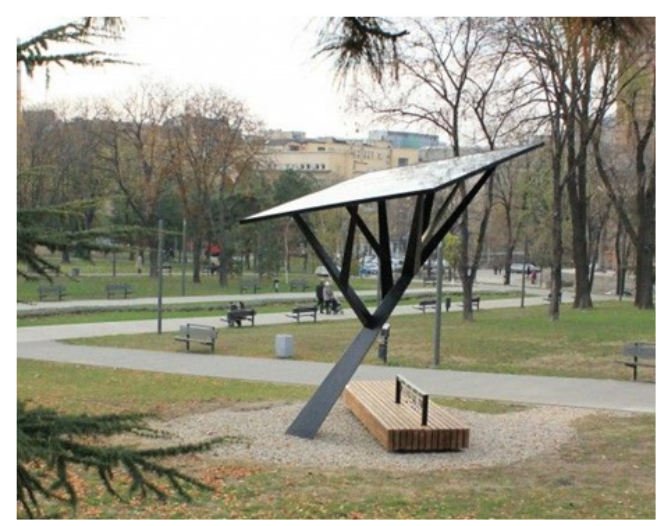

1a. Solar charger, Type A 


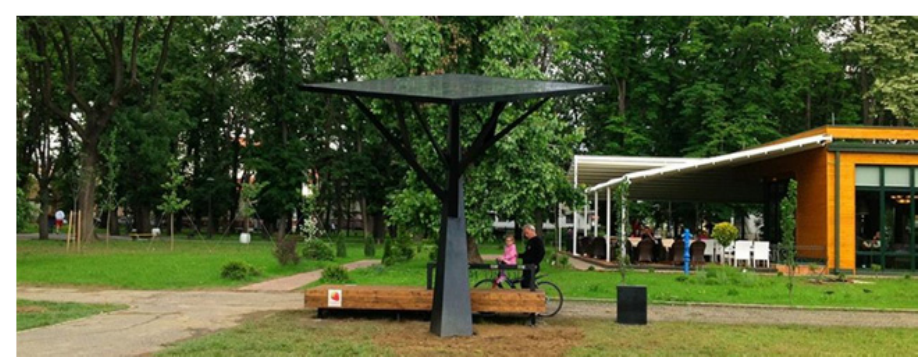

1b. Solar charger, Type B

Figure1. Solar chargers for portable devices made by Serbian Company Strawberry Energy (Goodwin, 2012)

The availability and use of information and communication technologies are a pre-requisite for economic and social development in our world. They are the functional equivalent of electricity in the industrial era (Castells, 1999, 3).

Alvin Toffler, a futurist, considered the advent of agriculture was the first wave of significant development in human life that took place some tens of thousands years ago.The second significant development was industrial revolution.Our generation belongs to the third wave which is referred to as information revolution. The third wave is the result of electronic advancements that has brought about a new way of living that relies on various sources of energy including renewable ones. This third revolution is built around production systems that has outdated mass production and is design based on a new entity called "electronic stand" (Toffler, 1384,17).

Requirements of life are changing daily and nowadays personal and social life is deeply depending on the use of electronic equipment.In this context, new types of street furniture are designed to meet these needs such as internet kiosks, information kiosks, electronic ticketing and ATM kiosks that cover the communication needs in outdoor or indoor spaces. The various kiosk specifications to meet the communication needs of citizens are as follows:

- $\quad$ Promotion of social welfare and living standards of citizens by creating a functional space for access to communications technology

- Improving and optimizing the quality of urban environments by providing various services requirements

- Creating a sense of vitality and safety for citizens in crowded cities because of providing better access to various services

- Identifying functions and creating cities with modern identities

- Meeting everyone needs by considering ergonomic principles in the Communication Age

- Providing justice by designing services for people with different physical abilities in accordance with the principles of the universal design

- $\quad$ Responding to a variety of psychological and physiological needs (according to the functionality of the interactive kiosks)

Information age and globalization make up a collection of processes which facilitates global cultural, social, economic, and political interactions.Devices which facilitate long distance communication including computers, satellites, news media, and other electronic infrastructures have created a continual development in global systems. These developments have improved living environment and urban spaces toward further uniformity and globalization. The change generated by technology is directed to more sustainable and equitable outcomes and improve access to opportunities provided by technology, particularly in developing countries (Dugarova \& Utting, 2013).Technology, including information and communication technology (ICT), is increasingly being seen as an important element in the contemporary sustainable development agenda. In this sense, technology is likely to play a major role in the transition to sustainable production and consumption (WESS, 2013).

Achieving global sustainability is a major challenge of the $21^{\text {st }}$ century.Attention to sustainable values and views play a vital role in facing such challenge because a scenario posits a world beyond 2050 in which the quality of human knowledge, creativity and self-realization are the measure of development, not the quantity of goods and services, while providing material sufficiency for all, it embraces equality, empowerment, and deep respect for 
the intrinsic values of nature (Leiserowitz et al., 2006).

\section{Assess the need and the statistical population description}

This study is descriptive-analysis research in which the need for design of urban charging kiosks, using the likert-type scale, was examined. The data were analyzed by using IBM SPSS Statistics 21 . Research validity and reliability through Cronbach's alpha of 0.86 for the items was confirmed. Simple and non-probable sampling method was chosen to avoid focusing on specific regional needs, and samples had been selected among passengers who were waiting in Mehrabad Airport in Tehran who usually use various types of electronic devices.

The research's statistical population included 90 persons.The following table represents the samples specifications. According to the results most responders were men between 25 to 40 years of age and their graduate degree was master or upper.

Table 1. Statistical population description

\begin{tabular}{llll}
\hline Variables & & f & $\%$ \\
\hline \multirow{4}{*}{ Gender } & Female & 38 & $42,2 \%$ \\
& Male & 52 & $57,7 \%$ \\
\hline & $10-25$ & 20 & $22,2 \%$ \\
& $25-40$ & 51 & $56,7 \%$ \\
Age & $40-55$ & 13 & $14,4 \%$ \\
& $55-70$ & 6 & $6,7 \%$ \\
\hline \multirow{4}{*}{ Education } & Pre Diploma & 4 & $4,4 \%$ \\
level & Diploma & 18 & $20 \%$ \\
Total & Post Diploma & 5 & $5,6 \%$ \\
& Bachelor & 30 & $33,3 \%$ \\
& Master or upper & 33 & $36,7 \%$ \\
\hline
\end{tabular}

For need evaluation, based on questionnaire and statistical considerations and normal distribution of data, One-Sample T-test was used.The results are summarized as follows:

Table 2. One-Sample T test results

\begin{tabular}{lllllll}
\hline Variable & Mean & Std. Deviation & Given mean & t & df & Sig. \\
\hline Level of need & 36,18 & 7,56 & 33 & 4,001 & 89 & 0,001 \\
\hline
\end{tabular}

The results of the test $(\mathrm{t}=4.001 \& \mathrm{p}<0.05)$ indicates that there is a significant difference between the level of need and given mean and the results show that the charging systems are today's outdoor necessities.

\section{Charger Station for Open and Green Areas}

Since mobile phones are ever-present tools in daily affairs, presence of charging stands supports continuous services while one spending time away from work devoted to rest and pleasure in open spaces of a city.Figure2 is showing a suggested design for a charger stand in open spaces. 

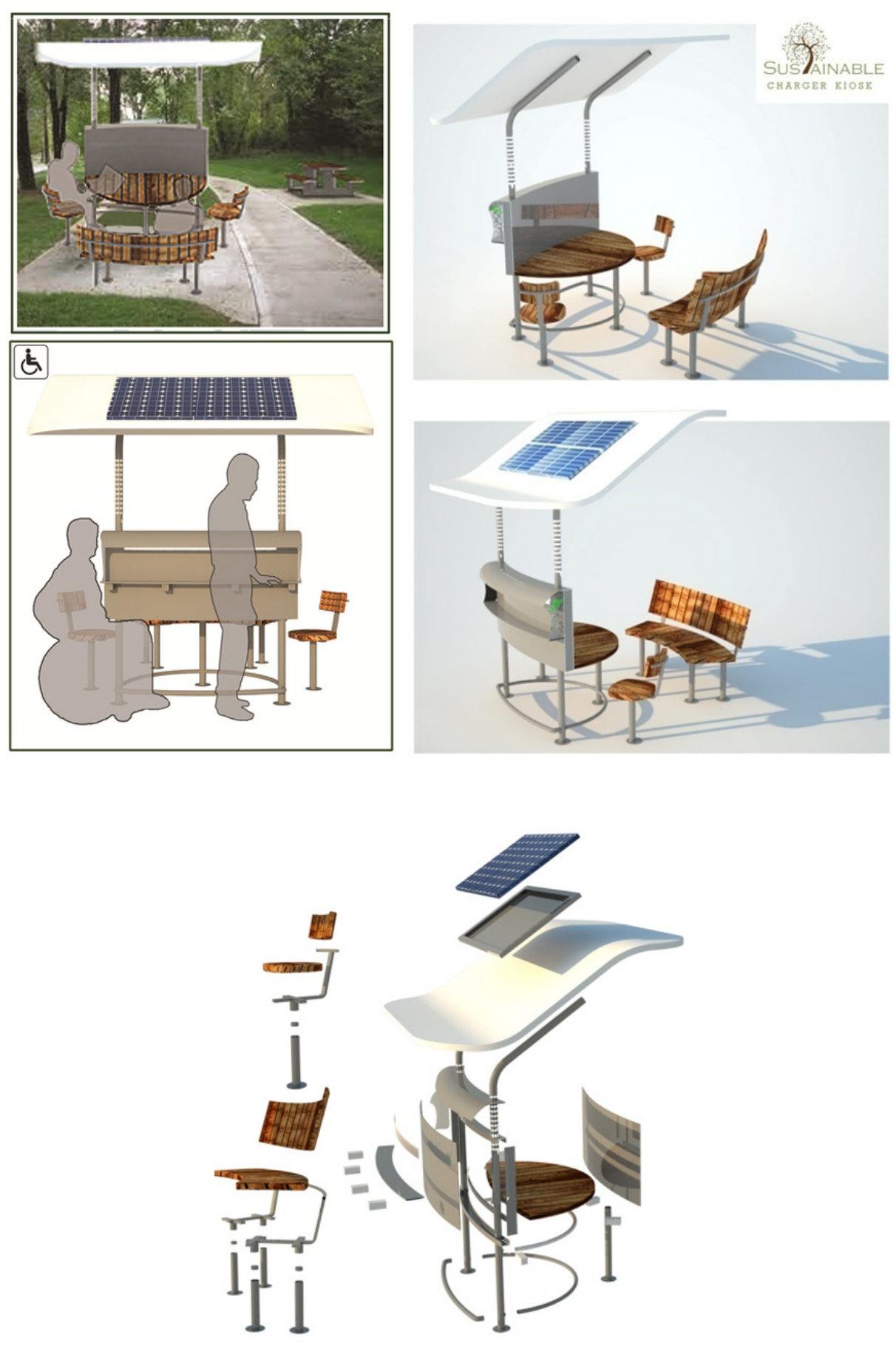

Figure2. Chargers stand for open spaces

Use of solar photovoltaic panels in this stand is a response to the demands for environmentally sustainable design. The rest of the materials, including aluminum and wood are also biodegradable and eco-friendly.Wooden appearance of the stand is compatible with its environment and its symmetric and stable structure makes it aesthetically more pleasant. As a meeting place and charging station, a particular chair setup has designed for enhancing social interactions.

\section{Results}

- $\quad$ Providing suitable urban services by designing functional equipments may lead to keep peace of mind 
in tough times, improve citizen participation and elevate public wellbeing.

- Stands for charging electronic devices fulfill the need of constant internet users in public open spaces.

- The design and style of charging stations can be effective in improving social interactions.

\section{References}

Castells, M., \& United Nations Research Institute for Social Development (UNRISD). (1999). Information Technology, Globalization and Social Development. ISSN 1012-6511

Dempsey, N., Brown, C., \& Bramley, G. (2012). The key to sustainable urban development in UK cities; The influence of density on social sustainability.Progress in Planning, 77(3), 89-141. http://dx.doi.org/10.1016/j.progress.2012.01.001

Dugarova, E.,\& Utting, P. (2013). The Social Drivers of Sustainable Development. United Nations Research Institute for Social Development(UNRISD)

Golipnik, B., \&Thompson, C. (2010). Emerging relationships between design and use of urban park spaces. Landscape and Urban Planning, 94(1), 38-53.http://dx.doi.org/10.1016/j.landurbplan.2009.07.016

Goodwin, A. (2012). Serbian Park Becomes Greener with Solar-Powered Charging Station. Retrieved from http://inhabitat.com/serbian-park-becomes-greener-with-solar-powered-charging-station/

Jamirsah, N. (2012). How Urban Green Space Design Affects Urban Residents'Social Interaction. 7th Singapore Graduate Forum on Southeast Asia Studies 2012 (Vol. 2012, pp. 1-13). Johor Bahru, Malaysia: Asia Research Institute, National University of Singapore.

Leiserowitz, A. A., Kates, R. W., \& Parris, T. M. (2006). Sustainability values, attitudes, and behaviors: A review of multinational and global trends. Annu. Rev. Environ. Resour., 31, 413-444. http://dx.doi.org/10.1146/annurev.energy.31.102505.133552

Peters, K., Elands, B., \& Buijs, A. (2010). Social interactions in urban parks: Stimulating social cohesion Urban Forestry \& Urban Greening, 9(2), 93-100.http://dx.doi.org/10.1016/j.ufug.2009.11.003

Rasidi, M. H., Jamirsah, N., \& Said, I. (2012). Urban Green Space Design Affects Urban Residents' Social $\begin{array}{lllll}\text { Interaction.Procedia-Social } \quad \text { and } & \text { Behavioral } & \text { Sciences, } & 68,480 .\end{array}$ http://dx.doi.org/10.1016/j.sbspro.2012.12.242

Redclift, M. (1993). Sustainable development: Needs, values, rights.Environmental Values, 2(1). 3-20. UK

Shu, C.,\& Huang, L.(2006). A study of outdoor interactional spaces in high-rise housing. Landscape and Urban Planning, 78, 193-204.http://dx.doi.org/ 10.1016/j.landurbplan.2005.07.008

Toffler, A.(1980). The Third Wave. Bantam Books, USA.

WESS (World Economic and Social Survey). (2013). Sustainable Development Challenges. UN DESA, New York.

\section{Copyrights}

Copyright for this article is retained by the author(s), with first publication rights granted to the journal.

This is an open-access article distributed under the terms and conditions of the Creative Commons Attribution license (http://creativecommons.org/licenses/by/3.0/). 